\title{
Marx's Analysis of the Falling Rate of Profit in the First Version of Volume III of Capital
}

\section{Howard Petith}

Department of Economics and Economic History, Universitat Autonoma de Barcelona, 08193 Bellaterra, Barcelona, Spain; Howard.Petith@uab.es

The paper provides a description and analysis of the Hodgskin section of Theories of Surplus Value and the general law section of the first version of Volume III of Capital. It then considers Part III of Volume III, the evolution of Marx's thought and various interpretations of his theory in the light of this analysis. It is suggested that Marx thought that the rate of profit must fall and even in the 1870s hoped to be able to provide a demonstration of this. However the main conclusions are:

1. Marx's major attempt to show that the rate of profit must fall occurred in the general law section.

2. Part III does not contain a demonstration that the rate of profit must fall.

3. Marx was never able to demonstrate that the rate of profit must fall and he was aware of this.

\section{Introduction}

In November of 1862 Marx was working on the final part of Theories of Surplus Value (TSV) when he encountered a serious problem. He was attempting to set out the argument of Thomas Hodgskin that the rate of profit would fall because capital grows faster than labour and found that he could not make the argument convincing. He broke off work on TSV and filled 350 notebook pages with what is the first version of Volume III of Capital, he then returned to the "Hodgskin section" and finally finished TSV. The 350 notebook pages contain a 50 printed page section called "General Law of the Fall of the Rate of Profit" which corresponds to Part III of Volume III, henceforth Part III. These 350 notebook pages appeared in English only in 1991 with the publication of Volume 33 of the Collected Works. ${ }^{2}$ The main contribution of the present paper is to provide the first detailed analysis of this "general law section".

After setting out a mathematical framework, the main part of the paper starts with a description of the Hodgskin section. Here Marx sets out two arguments: one which involves reducing the number of workers and a second which involves increasing the composition of capital. ${ }^{3} \mathrm{He}$ is dissatisfied with both. The paper next describes the 
general law section. Here Marx first repeats the increasing composition of capital argument. Next he adds the falling number of workers argument to this. Then finally, in what will be argued is his main attempt to show that the rate of profit must fall ${ }^{4}$, Marx lowers the number of workers while analytically keeping the total value of capital fixed. He is unable to complete the argument and thus his major attempt fails. This section of the paper finishes with a demonstration that, if Marx had been able to complete the argument, he would have shown that the rate of profit must fall, at least in a qualified sense. The rest of the paper discusses Part III, the evolution of Marx's thought and also various interpretations of Marx's theory all in the light of the Hodgskin and the general law sections.

\section{A Formal Model}

This section sets out a formal model that encompasses all of Marx's attempts to show that the rate of profit must fall. The model has one sector with labour as the sole basic factor, one good (which may be thought of as corn), a fixed coefficient technology and only circulating capital (capital is completely used up in production).

Specifically it is assumed that capital and labour are fully employed. This implies that

$$
\begin{aligned}
& k K=Y \\
& l L=Y
\end{aligned}
$$

where $K, L, Y, k$ and $l$ are capital, labour power measured in hours, output and the technically determined output to capital and output to labour power ratios. Labour power is called labour for short and $k$ and $l$ are called capital and labour productivity. ${ }^{5}$ The rate of profit is defined as

$$
r \equiv \frac{Y-K-w L}{K+w L}
$$

where $w$ is the real wage per hour, the wage for short. The value of a good $v$ is the amount of labour embodied in it. It is assumed that this is the sum of the labour and the value of the capital used to produce the good. It is also assumed that the value does not change over time. Thus $v=v(1 / k)+(1 / l)$ or

$$
v=\frac{(1 / l)}{1-(1 / k)}
$$

where $(1 / k)$ and $(1 / l)$ are, by definition, the capital and labour input coefficients. Constant capital $C$, variable capital $V$ and surplus value $S$ are defined as 


$$
\begin{aligned}
& C \equiv v K \\
& V \equiv v w L \\
& S \equiv v(Y-K-w L) .
\end{aligned}
$$

The model is comprised of three assumptions and four definitions which, together, take the form of seven equations in eleven variables $K, L, Y, k, l, r, w, v, C, V$, and $S$.

In addition there are two concepts and also two convenient equations which are implied by the model. The concepts are the composition of capital ${ }^{6}, C / V$ and the rate of surplus value, $S / V$. The two equations are

$$
\begin{aligned}
& r=\frac{1}{(1 / k)+w(1 / l)}-1 \\
& S=L(1-v w)
\end{aligned}
$$

At the most basic level Marx thought that, as capitalism developed, capital would grow faster than labour, that this would imply that constant capital grew faster than variable capital and that this last would cause the rate of profit to fall. ${ }^{7}$ But there was a wide gap between his intuitive and his formal approaches.

In his intuitive approach he emphasised that the increase in the composition of capital would cause labour productivity to rise.

If the ratio of the variable part of capital to the constant part...is large, ...this shows that all the means towards the development of the productivity of labour have not been employed. ...that therefore with a large quantity of labour little is produced, whereas in the opposite case a (relatively) large amount is produced with a small amount of labour.

The development of fixed capital...is a particular symptom of the development of capitalist production. (The general law section, Marx and Engels, 1991, p. 108)

To state this formally, there is what I shall call a labour productivity function $\tilde{l}(C / V)$ which relates labour productivity to the composition of capital,

$$
l=\tilde{l}(C / V), \quad \tilde{l}^{\prime}>0{ }^{8}
$$

Marx does not relate capital productivity to the composition of capital. But I will suppose that there is such a relation; that is,

$$
k=\tilde{k}(C V), \tilde{k}^{\prime}<0
$$

where the derivative must be negative if there is to be any possibility of the rate of profit falling. If Marx had been able to continue formally in this direction he would have seen immediately that his basic idea was wrong. From (8) 


$$
\frac{d r}{d(C / V)}<0 \text { if and only if }\left(\tilde{\mathrm{k}}^{\prime} / \mathrm{k}^{2}+w \tau^{\prime} / l^{2}\right)<0,
$$

that is, supposing that the wage is fixed, one must impose further conditions on the productivity functions if one wants to be sure that the rate of profit will fall.

Marx came to understand that he faced problems, but since he generally thought of the rate of profit as being determined by value variables rather than directly by productivities, he saw them differently. From (1)-(3) and (5)-(7)

$$
r=\frac{S}{C+V}=\frac{S / V}{C / V+1} \text {. }
$$

The direct effect of the rise in $C / V$ causes the rate of profit to fall. But Marx thought that the rise in labour productivity attendant on the rise in the composition of capital would cause the rate of surplus value to rise:

...the ratio of surplus value to the variable part of capital is smaller, the smaller is the ratio of variable capital to constant capital. (Marx and Engels, 1991, p. 107)

The model shows that he was correct: From (1), (2), (6) and (7)

$$
S / V=\tilde{l}(C / V)[1-(1 / k)] / w-1
$$

so that the direct effect of the rise in labour productivity caused by the rise in the composition of capital is to raise the rate of surplus value. Thus the problem, as Marx saw it, was to find a convincing way to limit the rise in the rate of surplus value so that the rate of profit would fall.

Although Marx perceived the problem as being caused by the rise in labour productivity, in his formal numerical examples he took an entirely different approach. As will be clear from the detailed descriptions that follow, his approach can be interpreted as follows. He would start with the basic model of (1)-(7) and then add four additional conditions to close the model. Three of these varied with the type of argument he was constructing, but the forth was that the wage was constant, $w=\mathbb{w}$, although this often was not explicitly stated. He would then pick a change in some variable that corresponded to capitalist development. Thus what Marx was trying to find were four conditions and a change that were both convincing and led to a fall in the rate of profit.

As we will see, these conditions do exist and Marx came within an ace of finding them. But this does not mean that his basic idea was correct. 


\section{The Hodgskin Section}

Thomas Hodgskin $(1966,1969$, originally published 1827, 1825) thought that capital would grow faster than labour and that this would cause the rate of profit to fall. In TSV Marx makes two attempts at a formal demonstration of this, the first involving a decrease in the quantity of labour and the second a rise in the composition of capital and finds that both fail. He then interrupts his work on Hodgskin to write the first version of Volume III.

\subsection{Reduction in the Number of Workers}

Starting on p. 298, Marx (1972) outlines Hodgskin's position on the falling rate of profit and then suddenly sets out his own first argument. He starts with a paragraph for the case in which the rate of surplus value is constant and another for the case in which it increases because the working day increases. Then, in three paragraphs of central importance, he sets out his argument for the case in which the rate of surplus value rises because the rise in the composition of capital has increased labour productivity; that is, the case of an increase in relative surplus value.

If the normal working-day remains the same, surplus labour can be increased relatively by reducing the necessary labour-time by ${ }^{9}$ reducing the prices of the necessaries which the worker consumes, in comparison with the development of the productive power of labour. But this very development of productive power reduces variable capital relative to constant. It is physically impossible that the surplus labour-time of, say, two men who displace twenty, can, by any conceivable increase of the absolute or relative [surplus] labour-time, equal that of the twenty. If each of the twenty men only work 2 hours of surplus labour a day, the total will be 40 hours of surplus labour, whereas the total life span of the two men amounts only to 48 hour in one day.

The value of labour-power does not fall in the same degree as the productivity of labour or capital increases. This increase in productive power likewise increases the ratio between constant and variable capital in all branches of industry which do not produce necessaries (either directly or indirectly) without giving rise to any kind of alteration in the value of labour. The development of productive power is not even. It is in the nature of capitalist production that it develops industry more rapidly that agriculture. This is not due to the nature of the land, but to the fact that, in order to be exploited really in accordance with its nature, land requires different social relations. Capitalist production turns toward the land only after its influence has exhausted it and after it has devastated its natural qualities. An additional factor is that, as a consequence of land ownership, agricultural products are expensive compared with other commodities, because they are sold at their value and are not reduced to their cost-price. They form, 
however, the principal constituent of the necessaries. Furthermore, if one-tenth of the land is dearer to exploit than the other nine-tenths, these latter are likewise hit "artificially" by this relative barrenness, as a result of the law of competition.

The rate of profit would in fact have to grow if the productivity of capital ${ }^{10}$ is to remain constant while accumulation of capital is taking place. The same worker, as long as capital yields 10 of surplus labour must, as soon as interest accumulates on interest and thus increases the capital employed, produce threefold, fourfold, fivefold in progression of compound interest, which is nonsense. (Marx, 1972, pp. 300-301)

These paragraphs are difficult to follow because Marx was trying to give form to his intuition rather than set out a formal analysis. In the first paragraph he sets out the argument for the falling rate of profit that involves a reduction in the number of workers and senses its weakness. Because of this, in the second paragraph, he adds a strong condition and four reasons for its satisfaction. Finally, the last paragraph indicates that the rate of profit falls because the condition is satisfied. One can use the formal model to see first, the argument and its weakness and second, why the satisfaction of the condition guarantees that the rate of profit will fall.

First consider the argument. To use the model one has to specify four additional conditions, reduce the quantity of labour, and then check the effect on the rate of profit. Suppose the four conditions are

$$
L=L, K=K, w=\pi \text { and one other chosen arbitrarily. }
$$

Here the barred variables are constants. Let $d \tau$ be the exogenous change in the labour supply and $d l, d k$ and $d r$ be the endogenously caused changes in labour and capital productivity and the rate of profit.

Proposition 1 Consider the model (1)-(7) with the additional conditions (12). Let $d L<0$. If $d L$ is large enough (absolutely) relative to $d l$ and $d k$ then $d r<0$; but if $d l>0$ and large enough (absolutely) relative to $d \bar{L}$ and $d k$, then $d r>0$.

Proof: From (11), (5), (6), (9), (4) and (12)

$$
r=\frac{S}{C+V}=\frac{\left[1-\frac{(1 / l)}{1-(1 / k)} w\right] L}{\frac{(1 / l)}{1-(1 / k)} K+\frac{(1 / l)}{1-(1 / k)} w L}=\frac{l-\frac{\bar{W}}{1-(1 / k)}}{\frac{1}{1-(1 / k)}(\bar{K}+W)},
$$

where the third expression is multiplied by $l / L$ to get the forth. Differentiating the last expression: if $d L$ is large enough (absolutely) relative to $d k$ and $d l$ then $d L<0$ implies $d r<0$. But if $d l>0$ and dominates, then $d r>0$. 
The line that Marx was following was that a reduction in $L$ would reduce surplus value relative to total capital and that this would cause a fall in the rate of profit. This can be seen from the third expression in the last sequence of equations with all other variables constant. But the weakness in the approach is that if labour productivity rose sufficiently it would raise surplus value and lower the value of total capital by enough to cause the rate of profit to increase. This can also be seen from the third expression. Thus what Marx needed was a condition that insures that the movements of $k$ and $L$ are large relative to that of $l$.

Second, consider the condition given at the beginning of the second paragraph. "The value of labour-power does not fall in the same degree as the productivity of labour...rises" ${ }^{\prime 11}$ One can use the model to see that this will guarantee a fall in the rate of profit. Suppose the additional conditions are

$$
w=\pi, L=L \text {, and two others which are chosen arbitrarily. }
$$

Let $\tilde{V}=w v$ be the value of labour power, $d L$ be the exogenous change in the labour supply, $d l, d \tilde{V}$ and $d r$ be the changes that are caused in the endogenous variables.

Proposition 2 Consider the model (1)-(7) with the additional relations (13). Let $r>0$. If the fall in the value of labour-power, $-d \tilde{V}>0$, is sufficiently smaller than the rise in labour productivity, $d l>0$, then $d r<0$.

Proof: From (4) one has

$$
1 / k=1-\frac{1}{v l}=1-\frac{w}{\tilde{V} l}
$$

Substituting this into (8) and using (13),

$$
r=\frac{1}{1-\frac{\bar{V}}{l}\left(\frac{1}{\tilde{V}}-1\right)}-1 \equiv r(l, \tilde{V}) .
$$

Since $r>0$, the preceding equation shows that $1-\frac{W}{l}\left(\frac{1}{\tilde{V}}-1\right)<1$ so that $\frac{1}{\tilde{V}}-1>0$ and thus $\partial \tilde{r} / \partial l<0$ and $\partial \tilde{r} / \partial \tilde{V}<0$. Since $d r=\frac{\partial \tilde{r}}{\partial l} d l-\frac{\partial \tilde{r}}{\partial \tilde{V}}(-d \tilde{V})$, the proposition follows.

The sense of the result is the following: Marx says that the rate of profit will fall if the productivity of labour rises by more than the value of labour power falls. Think of these two events happening in sequence. The only way that one of these can change while the other remains constant is if the change is compensated for by a change in the 
productivity of capital. Thus, first, when the productivity of labour rises the productivity of capital must fall so that the value of labour-power may remain constant and, as a result, the rate of profit falls $(\partial \tilde{r} / \partial l<0)$. Second when the value of labour power falls the productivity of capital must rise so that the productivity of labour may remain constant and as a result the rate of profit rises $(\partial \tilde{r} / \partial \tilde{V}<0)$. If the first effect is stronger the rate of profit falls. Thus the condition is a complicated way of ensuring that the fall in capital productivity $k$ is sufficiently large relative to the rise in labour productivity $l$. I do not want to claim that Marx had worked this all out in detail. But it is impressive that he could arrive at a condition whose intuition is somewhat complicated.

According to this interpretation of the three paragraphs, Marx had been unable to demonstrate that a reduction in the quantity of labour would lead, without further conditions, to a fall in the rate of profit.

\subsection{The Rise in the Composition of Capital}

Marx now returns to Hodgskin's argument and compares it to his own. Previously he had claimed that a fall in the proportion of variable capital to constant capital would cause a fall in the rate of profit. ${ }^{12}$ He portrays Hodgskin as claiming that an increase in constant capital relative to variable capital will do the same. "In its general sense this amounts to the same thing." (Marx, 1972, p. 302) He proceeds confidently with a number of examples in which he holds the rate of surplus value constant, raises constant capital and observes that the rate of profit falls.

He then sets out an example that reveals, it would seem to his surprise, the weakness of the argument:

Just as the worker produced [a profit of] 25 on [a capital of] 50, he now is expected to produce [a profit of] 100 on a capital of 200, or four times as much. But this is impossible. To do that, either the worker would have to work four times as long, that is 48 hours a day if he worked 12 hours previously or the value of labour-power would have to fall 75 percent as a result of increased productivity of labour. (Marx, 1972, p. 304)

In the next paragraph Marx first keeps the productivity of labour constant and shows in a number of ways that the rate of profit can not be maintained with the larger constant capital per worker. He then broaches the possibility of an increase in productive power.

No matter how much the productive power increases [if, in the above example, the value of 12 hours was 37.5 then that of 24 hour adds to $2 \times 37.5$ or 75 . And 
since a worker must live he can never produce 75 profit, much less 100]. ${ }^{13}$ (Marx, 1972, p. 304)

On the face of it the example purports to be a demonstration that the rate of profit must fall. But Marx's indication that it will not fall if the growth of labour productivity is sufficiently large shows that Marx has discovered the weakness in the argument. The example is more complicated than it first appears. I will first give a simple but imprecise interpretation of the example that brings out clearly the problem with the argument as Marx perceived it. I will then indicate the difficulties and finally I will show, with the help of the model, that the problem that Marx perceived was a real one.

The simple interpretation is as follows. In the part quoted Marx just has numbers but in other parts of the same example he refers to pounds. Let the price of the good be fixed in pounds and furthermore make the assumption, which is not innocuous, that the value of a pound and the value of labour power are also fixed. Using (11) the four cases can be set out as in Table 1 .

$\begin{array}{lcccc} & C & V & S & r \\ I & 25 & 25 & 25 & 50 \\ I I & 175 & 25 & 25 & 12.5 \\ I I I & 175 & 25 & 100 & 50 \\ I V & 175 & 25 & 50 & 25\end{array}$

Table 1

In case I the net output, that is output after capital has been replaced, produced by the worker is 50 of which 25 is salary and 25 surplus value so that the rate of profit is $50 \%$. In case II constant capital has increased but the worker's net output is constant at 50 so the rate of profit falls to $12.5 \%$. In case III, which is the one in which Marx says that the value of labour power falls by $75 \%$, the increase in constant capital has raised the worker's net productivity to 125 . He is still paid 25 , surplus value is 100 and the rate of profit is still $50 \%$. This case shows that Marx does not have an argument since, if the increase in constant capital sufficiently raises the worker's net productivity, the rate of profit will not fall. Marx's response in case IV is a non sequitur. He just shows that if the worker's net output rises only to 75, then the rate of profit must fall. But Marx gives no reason why there should be this limit on net output. This, I think, is the problem as Marx perceived it.

The problem with the example is that the value of the good depends on the productivity of capital and labour (Equation 4). Since these change from case to case the 
assumption that the value of the good is constant is violated. Marx actually touches lightly on this in case III when he says that the rise in labour productivity will lower the value of labour power. In this case the value of 25 will hire additional workers which are, presumably, the source of the increase in income. If one tries to take account of these changes, the example rapidly becomes too complex to handle. Thus it is not clear whether the problem that Marx perceived is a real one.

One can use the model to show that it is. The question is the following: is it possible that an increase in $C / V$ will cause such a large increase in labour productivity that the rate of profit will remain constant? In terms of the model one can state the question as follows: Consider the model of (1)-(7) with the additional conditions

$$
L=L, w=\varpi, C / V=\overline{C / V} \text { and } l=\tilde{l}(C / V) .
$$

Can one find a labour productivity function $\tilde{l}$ such that $d r / d \overline{C / V}=0$ ? The answer is given by the following proposition.

Proposition 3 Consider the model of (1)-(7) with the additional conditions (14). If $\mathcal{l}=\mathbb{W}\left(\frac{C}{V}+1\right)\left(r^{*}+1\right)$, where $r^{*}$ is a parameter, then $d r / d \overline{C / V}=0$.

Proof: From (1) and (2), $k=(L / K) l$. Substituting this into (8) and using (5) and (6) gives

$$
r=\frac{l}{\frac{K}{L}+\varpi}-1=\frac{\varpi\left(\frac{K}{\pi L}+1\right)\left(r^{*}+1\right)}{\frac{K}{L}+\varpi}-1=r^{*} .
$$

The proposition follows immediately.

According to this interpretation, Marx came to correctly understand that a rise in the composition of capital did not imply, at least in a straight forward way, that the rate of profit must fall.

\subsection{The Rest of the Hodgskin Section}

In the rest of the section Marx rambles on generally but does not manage to come to grips with the basic issue. First (Marx, 1972, p. 305) he looks at the example again but only notes that if the worker works more for the capitalist, then the rate of profit will rise. Next there is a long section (pp. 305-307) where he says essentially that the issue arises because capital grows faster than labour. Finally he returns to the question of why the rate of profit will fall when constant capital increases. He first deals easily with the 
case of unchanged labour productivity (pp. 307-310). He then turns to the key case in which labour productivity increases and cops out. He writes paragraphs on the following: concentration, a reference back to three quoted paragraphs (pp. 300-301) and finally the effect of increases in wages on the rate of profit. There is a short unrelated section and then the break of 350 notebook pages occurs in which Marx wrote the first version of Volume III.

\subsection{Conclusion}

The Hodgskin section contains two problematic arguments that the rate of profit must fall. In the first Marx had to impose a strong condition to ensure that a fall in the number of workers would imply a fall in the rate of profit. While, in the second, he could find no way to exclude examples in which the rate of profit did not fall in spite of the rise in the composition of capital. Although he does not say it specifically, I think that Marx could not have been satisfied that he had shown that the rate of profit must fall. One can imagine that it was this dissatisfaction that, in part, caused him to write the first version of Volume III.

\section{The General Law Section}

The general law section corresponds roughly to Part III of Volume III (Marx, 1959, pp. 211-260). Three topics are discussed below: Marx's claim that the falling rate of profit can be discussed in terms of a one sector model; the failure of Marx's major attempt to show the rate of profit must fall; and finally the demonstration that, under the conditions that Marx imposed, the rate of profit must fall.

\subsection{The Sufficiency of the One Sector Model}

Marx opens the general law section with the claim that he can analyse the rate of profit in terms of a one sector model. He bases this claim on the previous section. The previous section, “The Costs of Production", (Marx and Engels, 1991, pp. 78-103) corresponds roughly to Part II of Volume III (Marx, 1959, pp. 142-210). In Part II Marx makes it clear that there are two ways to calculate the rate of profit: one can use prices of production and then all industries have the same rate of profit or one can use values, in which case the sum of surplus values divided by the sum of total capital, both taken across industries will give the same rate of profit. (see Marx, 1957, pp. 156-157). In the 
costs of production section, pp .90-100, Marx seems to make the same point but with such little clarity that one must know it in advance to see it.

It is to this idea that he refers in the opening paragraph of the general law section:

We have seen that real profit-i.e. the current average profit and its rate-is different for the individual capitals from profit, in so far as the latter consists of surplus value really produced by the individual capital and the rate of profit therefore $=$ the ratio of the surplus value to the total amount of capital advanced. But it was also shown that considering the total capital of the capitalist class, the average rate of profit is nothing other than the total surplus value related to the total capital exactly in the way in which profit-and therefore the rate of profit-is related to individual capital, in so far as profit is considered only as surplus value which has been converted formally. Here, therefore we once again stand on firm ground, where, without entering into the competition of many capitals, we can derive the general law directly from the general nature of capital as so far developed. This law, and it is the most important law of political economy, is that the rate of profit has a tendency to fall with the progress of capitalist production. (Marx and Engels, 1991, p. 104)

The overall message is clear. Up to "Here, therefore..." it is helpful to keep the cited part of Volume III in mind. But after this one needs no help. Because the rate of profit is surplus value divided by the value of total capital, it can be analysed in terms of these aggregates. This paragraph is important, not because it explains at all why the rate of profit falls, but rather because it justifies interpreting Marx's explanation in terms of a one sector model.

\subsection{Marx's Major Attempt and Its Failure}

After this first paragraph, Marx delays his attack:

So where does this tendency for the general rate of profit to fall come from? Before this question is answered, one may point out...(Marx and Engels, 1991, p. 104).

Then on p. 109 he starts in earnest. There is a long paragraph that starts "The development of productive power has a double manifestation:" (Marx and Engels, 1991, p. 104). Here he is referring to the opposite effects of rises in $C / V$ and $S / V$. This made clear by the example that follows:

If $C=500, c=100, v=400$ and $S=60, S / v=15 \%$ so that the rate of profit $=60 / 500=$ $12 \% .{ }^{14}$ Furthermore, if $C=500, c=400, v=100$ and $S=30, S / v=30 \%$, so that the rate of profit $=30 / 500=6 \%$. The rate of surplus value is doubled, the rate of profit is halved. ... for the rate of profit to be $12 \%$ surplus value would have to be $60 ; S / v=60 / 100=60 \%$. 
For the rate of profit to remain the same, the rate of surplus value ... would have to grow in the same ratio as the magnitude of capital laid out in labour grows, in the same way as the magnitude of variable capital falls relatively, or the magnitude of constant capital grows relatively. It is already strikingly apparent from a single circumstance that this is only possible within certain limits, and that it is rather the reverse, the tendency towards a fall in profit-or a relative decline in the amount of surplus value-which must predominate, as is also confirmed by experience. (Marx and Engels, 1991, p. 110).

This long quote gives the impression that Marx is confident that he will be able to show that the rate of profit must fall, but that he is not exactly sure how he will do it.

Over the next ten pages Marx slowly convinces himself that he will not be able to show that the rate of profit must fall, at least if he restricts himself only to the quantities of constant and variable capital and surplus value. First he works roughly through a number of examples and finds no way that he can show that the rate of profit must fall.

Then he begins to work on oversize pages which he glues into the notebook and writes "Let us first assemble the facts" (Marx and Engels, 1991, p. 117). ${ }^{15}$ He then constructs the following very careful example with four cases in all of which the rate of profit and variable capital remain constant. They are shown in Table 2.

$\begin{array}{cccccc} & c & v & S & p^{\prime} & s^{\prime} \\ I & 200 & 600 & 120 & 15 & 20 \\ I I & 600 & 600 & 180 & 15 & 30 \\ I I I & 1200 & 600 & 270 & 15 & 45 \\ I V & 3000 & 600 & 540 & 15 & 90\end{array}$

Table 2

He considers a number of different relations but he has two main conclusions. The first is:

If in the second case indicated above, the rate of profit is to remain the same, the profit, hence the surplus value will have to rise from 120 to 180 i.e. by 60 or $1 / 2$ of 120 , rise by half its original magnitude. The surplus value would therefore have directly to grow in the same proportion as total capital by 50\%. (Marx and Engels, 1991, pp. 118-119)

Marx then checks that this property holds for the other two cases. His second conclusion is 
The rate of surplus value would therefore have to [grow] directly [as the] total capital grew... for the rate of profit to remain unaltered... (Marx and Engels, 1991, p. 119)

This last holds only when variable capital is held fixed as it is here. The key aspects of this example are the care taken and its length (2 pages). Marx had got all he could out of this format and had not been able to show that the rate of profit must fall. ${ }^{16}$ If he was going to do it, he saw that he would have to use a more powerful argument.

Marx then makes his first attempt to link the rising composition of capital and falling quantity of labour arguments.

[Surplus value] and the rate of surplus value, which is an identical relation if variable capital remains the same, does not grow as capital grows or variable capital [falls in relation to] total capital. There is absolutely no reason why the rise in productive power should observe exactly the same numerical ratio. It [insures that the size] of relative surplus value grows and its growth is expressed in the ratio of the reduction in variable to total capital, but not in the same ratio as this proportion declines. Productive power grows hence surplus labour. Firstly there lies here [the heart of] the matter. One man may produce as much use value as 90. Never more than an average of 12 hours a day in value is [produced by a single worker], as this yields surplus value (of) never more than 12 hours $-\mathrm{x}$, where $\mathrm{x}$ expressed the labour time necessary for his own production. The surplus value [which is part of the total value the single worker produces, is limited by] the labour time which he himself works, not by the working days he replaces. If 90 men only worked $1 / 2$ an hour of surplus time a day, this would be [45] hours. If one man needed only one hour of necessary labour time, he would never [produce] more than 11 hours of surplus value. (Marx and Engels, 1991, p. 120)

The rising composition of capital argument, which is not stated very clearly, ends with “...hence surplus labour". The falling quantity of labour argument starts with "Firstly, there lies here the heart of the matter.”. But the arguments are just placed in sequence, they are not interconnected.

Marx then draws a line, writes $[\alpha]$ and tries more seriously to link the two arguments:

[Machinery] now evidently has a tendency to affect the two factors of surplus value in opposite directions. It increases the rate [of surplus value and] reduces the number of workers // relatively anyway; with respect to a definite measure of capital e.g. percent //, whose labour [by this means] is exploited at an increased rate. (Marx and Engels, 1991, p. 123)

He then sets out the following example, illustrated in Table 3, 


$\begin{array}{cccccc}\text { case } & n & S L / n & N L / n & S L & N L \\ 0 & 12 & 1 & 11 & 12 & 132 \\ 1 & 12 & \uparrow & \downarrow & \uparrow & \downarrow \\ 2 & 6 & 2 & 10 & 12 & 60\end{array}$

Table 3

where the working day is 12 hours and the variables are, respectively, the number of workers, surplus and necessary labour per capita and total surplus and necessary labour.

The arrows give the first case relative to case 0 . He then states

[In the first case a process] of simple co-operation and division of labour takes place. This is as with [an increase in production caused by having the worker use a better tool. The second case is different.] Relatively to the product [that is, to a fixed number of units] the number of workers is reduced [. Also there is a reduction of the number of ] workers [relative to a fixed total ] capital $C$ [and also relative to] constant [capital $c$ so that, regarding labour,] with machinery an absolute reduction (with regard to a particular capital) takes place. (Marx and Engels, 1991, p. 124)

And again:

It is now an entirely self-evident general law that with the progressive employment of machinery, the magnitude [of surplus value cannot] remain but must fall; i.e. that the reduction of the number of [workers] (in relation to a particular measure of capital) [must cause a fall in surplus value.] (Marx and Engels, 1991, p. 124-125)

Marx's intention here is the following: He wants to reduce labour and increase machinery in such a way that total capital remains fixed. Then he will use the reduction in labour to cause surplus value and thus the rate of profit to fall.

But he can't complete the argument. Instead he ends with an unconnected example in which 5 workers replace 50 which shows that

there therefore takes place [a change], so large that the reduction in the absolute amount of labour employed, [cannot be compensated for] by an increase of equal size in the rate of surplus value-where surplus value therefore falls in spite of the growth in the rate of surplus value. (Marx and Engels, 1991, p. 125)

But he cannot show that the "particular measure of capital" has remained unchanged because this was never a formal part of the example. Thus he cannot claim that he has shown that the rate of profit must fall and does not make this claim. 
He now writes $\beta$ and finally begins to construct an example in which both the number of labours and the value of total capital appear. Let $n$ be the number of workers and $h$ the hours that each works so that

$$
L=n h \text {. }
$$

The example is set out in the first four columns of Table 4.

$$
\begin{array}{cccccccccc} 
& V & C & n & v w h & h & S & r & Y & v \\
I & 400 & 200 & 10 & 40 & 80 & 400 & 0.66 & 1000 & 1 \\
I I & 80 & 520 & 2 & 40 & 80 & 80 & 0.13 & 1000 & 0.68 \\
& \multicolumn{5}{c}{\text { Table } 4} & & & &
\end{array}
$$

$v w h$ is the wage payment per worker in value terms. In case I $C$ is 150 of raw material and 50 of machinery while in case II $C$ is 150 of raw material and 370 of machinery, so that the raw material is the same in both cases. In addition output in physical units is the same (this is the reason why raw materials are equal in both cases). Marx notes that total capital is the same in both cases but that the composition of capital is higher in case II. Finally he has a model in which total capital can formally be kept constant at the same time as the number of workers is reduced.

On can see where he is trying to go. The example can be finished, for example, by specifying $h=80$ and then calculating $S$ from (15) and (9) and then $r$ from (11) for the both cases. This is done in the next three columns of Table 4. This is the argument Marx had been searching for: with total capital fixed, reducing the number of workers lowers surplus value and the rate of profit convincingly falls!

But there is a problem. With physical output fixed, the value of a unit of output has fallen. Suppose output is 1000 units. Then in case I the value of a unit is 1 and in case II it is $680 / 1000=0.68$. These are the next two columns of Table 4 . Thus the case II wage in value terms should be reduced to keep the real wage constant. The simple argument that Marx hoped to make is not viable. But at least in this framework the basic problem can be confronted.

Marx realises this :

Nevertheless, the quantities of commodities produced under the changed conditions of production might on certain presuppositions become cheaper, (Marx and Engels, 1991, pp. 125-126) 
He than sets about calculating the prices in both cases so that, presumably, he can see how much the wage in value terms in case II should be lowered. He starts with case II:

Assume now that the machinery employed has a turn over time //reproduction time// of 10 years. Of the value employed, 37 (370/10) would enter into the annual output of the commodities for the replacement, wear and tear, of the machinery. The sum total of the production costs of the commodities //disregarding profit and surplus value here, as the rate remains the same// would now be = $37+150+80=267$. The production cost of the commodity under the old process $=$ 600 , whereby we assume that the instruments which enter into the process (estimated at 150) must be renewed every year. ${ }^{17}$ The price of the commodities would have been cheapened in the ratio 267:600. (Marx and Engels, 1991, p.126)

He then realises that he only has production costs, not prices and corrects:

Even if we disregard the relation itself, and consider the empirical form, in which the capitalist calculates interest, say 5\% on 300 (the part of capital not consumed in the first year) $=15$ or $5 \%$ profit e.g., similarly 15 , therefore 30 . Thus the price of commodities would come to $280+30=310$ still almost half as cheap as in the first case.(Marx and Engels, 1991, p. 126) ${ }^{18}$

Marx is now very close to the result he wants. Suppose that the value of the commodity is halved, as Marx says. Then $v w h$ must be set equal to 20 to keep the real wage constant. Supposing that $C$ remains unchanged, one can construct case II' and see if the rate of profit still falls even when the wage in value terms is reduced. This is done in Table 5.

$$
\begin{array}{cccccccc} 
& V & C & n & w v h & h & S & r \\
\text { II } & 40 & 520 & 2 & 20 & 80 & 128 & 0.23 \\
& \multicolumn{4}{c}{\text { Table } 5} & & &
\end{array}
$$

The answer is that the rate of profit falls from 0.66 to 0.23 in spite of the fall in the value wage. This is the result that Marx was after.

But Marx does not do this. Perhaps surprised by how much the price of the good had fallen and suspecting that this would cause the rate of profit to rise, he constructs case III in which the machine lasts 20 years and has a value of 2000 . He calculates the price to be 528 and notes that it is now more expensive than the 310 of case II.

At this point Marx still could have calculated the rate of profit and found that it would have fallen. But instead of this he seems to have become distracted by the details of the relation between cases II and III. In case III the higher cost of the machine raises the price while the longer turnover time lowers it. He spends most of page 127 
discussing this, realises he is loosing the thread and writes "this belongs to the section on production costs just as the previous comments on surplus value must be treated under the heading of surplus value." (Marx and Engels, 1991, p. 128)

In the pages that follow one can find no coherent one sector argument that the rate of profit must fall. ${ }^{19}$ Thus Marx was very close to showing what he wanted to but failed. What happened? One can not be sure, but the following seems reasonable to me. It is not hard to formally reconstruct the argument at which Marx was aiming using the techniques of mathematical economics that have evolved in the century and a half since Marx wrote. But Marx was running on pure intuition with the scant aid of numerical examples. Intuition is a will-of-the-wisp and when it vanishes one is lost. I think that this is what happened at the moment where Marx lost the thread.

\subsection{Marx's Example with Circulating Capital}

In the preceding section Marx's example was set out and then it was demonstrated that Marx could have used this example to show that the rate of profit must fall. This demonstration was not quite legitimate. Marx's example had fixed capital, while the equations used were from the model with only circulating capital. Thus the question is still open as to whether the rate of profit must fall.

The following proposition shows that, at least for the circulating capital model and regardless of the particular numbers used, when the number of workers is reduce with total capital, the wage and output held fixed, the rate of profit must fall and will actually approach zero.

Proposition 4 Consider the model of (1)-(7) with the additional relations $C+V=\overline{C+V}, L=L, w=\bar{W}$, and $Y=\bar{Y}$. Then $d r / d \bar{L}>0$ and $\lim _{\bar{L} \rightarrow 0} r=0$.

Proof: The strategy of the proof is to express $S$ only in terms of the variables that are fixed. From (1) and (2), (1/l)=L/Y and $K=(1 / k) Y$. From (4)-(6)

$$
C+V=\frac{L / Y}{1-(1 / k)}[(1 / k) Y+w L] .
$$

Solving for $(1 / k)$ gives

$$
(1 / k)=\frac{C+V-w L^{2} / Y}{C+V+L}
$$

so that 


$$
1-(1 / k)=\frac{L(1+L w / Y)}{C+V+L}
$$

and from (4)

$$
v=\frac{C+V+L}{Y+L w}
$$

Substituting this into (9) and replacing the variables by their fixed values

$$
S=\frac{\bar{Y}-(\overline{C+V}) \bar{T}}{\bar{Y} / L+W} .
$$

Thus $d S / d L>0$ and $\lim _{L \rightarrow 0} S=0$. The result follows from (11).

I think that one can not fail to be impressed by this. Marx instinctively picked an example that implied that the rate of profit must fall. It appears at first glance that he could have shown that, without restrictions, the rate of profit must fall. But this is an illusion. As the expressions for $(1 / l)$ and $(1 / k)$ in the proof show, the conditions that $Y$ and $C+V$ be constant have imposed restrictions on the productivity functions.

\subsection{Conclusion}

I think that in the general law section, Marx tried to demonstrate that the rate of profit must fall, that he failed to do this and that he knew he had failed. First, if he had only wished to show that it might fall, he could have stopped virtually at the beginning after he had demonstrated that if the rise in the rate of surplus value was not large the rate of profit would fall. Second, it is incontestable that he failed since what he was trying to demonstrate is false. Third, Marx never says that he failed so that there is no textual evidence for this assertion. But the careful analysis of Marx's arguments shows that he was aware of what he had to demonstrate. And, given this, he had to know that he had not done it.

\section{Implications of the Hodgskin and General Law Sections}

The preceding analysis casts new light on Part III, the evolution of Marx's thinking and the various interpretations of his theory of the falling rate of profit.

\subsection{Part III}

It will be argued first, that Marx did not attempt to show that the rate of profit must fall and second that his change of approach could imply that he thought that the rate of profit might not fall. 
Two sections of Part III could be taken as demonstrations. Part III opens (Marx, 1957, pp. 211-212) with an exposition of the rising composition of capital argument in terms of a detailed example in which the rate of surplus value is held constant. Further along (p. 247) the falling quantity of labour argument is clearly stated. The purpose of the first of these, I think, is to indicate loosely to the reader why he should expect that the rate of profit will fall since the consequences of this fall are the main topic of Part III. The purpose of the second, I think, is to serve as one of the examples of contradictions in capitalist development since this is the theme of the subsection in which it appears. It is emphasised that the fall in the number of workers and the rise in the rate of surplus value have opposite effects on surplus value and the rate of profit.

But in any case, and this is the main point, these two sections can not be taken as demonstrations that the rate of profit must fall. With regard to the first, in both the Hodgskin and general law sections Marx had shown that the rise in the rate of surplus value attendant on the rise in the composition of capital could be sufficient to make the rate of profit rise. With regard to the second, in the Hodgskin section he had indicated that a strong condition had to be imposed to make the argument work. While in the general law section he had shown himself aware that a fall in surplus value was not sufficient to make the rate of profit fall, one had also to ensure that total capital remained constant. Given that Marx was aware of these problems, it is not possible that he would have inserted the two arguments as demonstrations that the rate of profit must fall.

The change in approach between the general law section and Part III raises a question as to Marx's beliefs. In the general law section, Marx set out a number of examples in which the rise in the rate of surplus value was considered simultaneously with the rise in the composition of capital. Marx's line of attack was to try to find a limit to the rise in the rate of surplus value so that he could claim that the rate of profit must fall. In Part III, on the other hand, the two are separated. The effect of the rise in the composition of capital is looked at first and called the law as such. Then, in the section on countervailing forces, the effect of the rising rate of surplus value is taken into account. Since this separation opens the possibility that the second effect could be stronger, it raises the question of whether, after he had finished Part III, Marx still believed that the rate of profit must fall.

\subsection{Chapter 3}


Because Chapter 3 of Volume III (Marx, 1957, pp. 49-69) was compiled partially from Marx's writing in the 1870 s, it gives some indication of his thinking after he wrote Part III.

Since it is less well known than Part III, I will give a brief résumé of the salient facts. This chapter was compiled by Engels and Samuel More from notes in the main manuscript which dated from 1864-1865 and a notebook filled with calculations that dated from the 1870s (Marx, 1957, p. 3). A notebook is typically equivalent to 200 printed pages. ${ }^{20}$ In the chapter, the formula

$$
p^{\prime}=s^{\prime} \frac{v}{C}
$$

is studied in detail (see footnote 13 for notation). Marx systematically varies the three elements on the right and looks at the effects on $p^{\prime}$. Each variation is explained in terms of changes in hours, wages, intensity of labour or the composition of capital, which he refers to as labour productivity. With two exceptions none of the changes are related to trends which are caused by capitalist development. Thus the chapter is an exercise and cannot be considered generally as an attempt to explain the movements of the rate of profit.

I think that the chapter and more especially the existence of the notebook lends weight to the idea that, after Marx wrote Part III, he still thought that the rate of profit must fall and that he would be able to demonstrate it: One has to ask why Marx would fill the equivalent of 200 printed pages with manipulations of (15) that bordered on the obsessive. One answer that comes immediately to mind is that he was looking for an argument that the rate of profit must fall. Undoubtedly there are others; but I find it difficult to think of any that are equally as convincing.

\subsection{Other Interpretations}

The preceding has implications for various interpretation of Marx's work.

1. It is generally held that Part III is Marx's main attempt to show that the rate of profit must fall. I have argued that this is not the case.

2. Some authors take Marx of Part III for the authority for arguments that the rate of profit must fall: Okishio (1970); Rosdolsky (1977, pp. 408-410); Shaikh (1978, p. 240) and Tsoulfidis (2002). If one accepts that Marx knew that the Part III arguments were faulty, this is not valid. 
3. There is a group of authors that attribute the falling rate of profit to a rising wage. They divide into two sections: those like Robinson (1942, p. 36) and Sweezy (1942, Ch. 6) who thought that Marx did not realise that the falling rate of profit plus his other assumptions implied a rise in the wage and those like Foley (1986, pp. 138139) and Duménil \& Lévy (forthcoming) who claim that Marx wanted to base the falling rate of profit on a rising wage. The discovery that, in his main attempt to show that the rate of profit must fall, Marx was at great pains to keep the wage constant cast doubts on all of this.

4. Some authors claim that Part III does not contain a demonstration that the rate of profit must fall: Fine \& Harris (1979, Ch. 4); Weeks (1981, Ch. 8); Fine (1989, Ch. 10) and Reuten (2002). This is a minority view but it receives strong support from the analysis of this paper. However, these authors then claim that this implies that Marx thought that the rate of profit might not fall and specifically that he used the word, tendency, to indicate this (Fine, 1989, pp. 65-66). The interpretation of Chapter 3 above weakens the general claim and the use of the word "tendency" in the general law section, which was clearly aimed at showing that the rate of profit must fall, casts doubts on the specific claim.

This brief resume shows that the analysis of Chapter 3 and especially of the Hodgskin and general law sections can cast new light on the various interpretations of Marx's theory of the falling rate of profit.

\section{Conclusion}

It has been argued that it is likely that Marx always believed that the rate of profit must fall and that in the 1870s he was still trying to demonstrate this. But the Main conclusions are:

1. Marx's main attempt to show that the rate of profit must fall occurred in the general law section.

2. In Part III, Marx did not attempt to show that the rate of profit must fall.

3. Marx never was able to construct a demonstration that the rate of profit must fall and he was aware of this. 


\section{References}

Duménil, G. \& D. Lévy (forthcoming) Technology and Distribution: Historical Trajectories a la Marx, Journal of Economic Behaviour and Organization.

Foley, D. (1986) Understanding Capital (Cambridge, Mass, Harvard University Press). Fine, B. (1989) $3^{\text {rd }}$. Edn. Marx's Capital (Basingstoke, Macmillan).

Fine, B. \& L. Harris (1979) Rereading Capital (New York, Columbia University Press). Hodgskin, T. (1966) Popular Political Economy, Reprint (New York, Augustus M. Kelley).

Hodgskin, T. (1969) Labour Defended Against the Claims of Capital. Or, The Unproductiveness of Capital Proved with Reference to the Present Combinations Amongst Journeymen, Reprint (New York, Augustus M. Kelley).

Marx, K. (1959) Capital (London, Lawrence \& Wishart).

Marx. K. (1968, 1972) Theories of Surplus Value, Parts II and III (London, Lawrence $\&$ Wishart).

Marx K. \& F. Engels (1989, 1991) Collected Works, Vols. 32 and 33 (London, Lawrence \& Wishart).

Okishio, N. (1977) Notes on Technical Progress and Capitalist Society, Cambridge Journal of Economics 1, pp. 93-100.

Petith, H. (2001) A Descriptive and Analytic Look at Marx's Own Explanations for the Falling Rate of Profit (Long Version) UAB Working Paper 524.02, available at http:// www.iea-csic.uab.es.

Reuten, G. (2002) The Rate of Profit Cycle and the Opposition between Managerial and Finance Capital: A Discussion of Capital III, Parts Three to Five, Ch. 6, in: A. Campbell and G. Reuten, eds. The Culmination of Capital: Essays on Volume III of Marx's "Capital"(Hampshire, Palgrave).

Robinson, J. (1942) An Essay on Marxian Economics (London, Macmillan).

Rosdolsky, R. (1977) The Making of Marx's Capital (London, Pluto Press).

Sadd-Filho, A. (2002) The Value of Marx (London, Routledge).

Shaikh, A. (1978) Political Economy and Capitalism: Notes on Dobb's Theory of Crisis Cambridge Journal of Economics, 2, pp. 233-351.

Sweezy, P. (1942) The Theory of Capitalist Development (New York, The Monthly Review Press).

Tsoulfidis, L. (2002) Classical, Neo-classical, and Marxian Perspectives on the Falling Rate of Profit and the Tendency to Crisis, Paper presented at ESHET 2002.

Weeks, J. (1981) Capital and Exploitation (London, Edward Arnold).

\footnotetext{
${ }^{1}$ This paper first appeared as UAB working paper 297.95. I have benefited from the comments of Giovanni Bono, Tony Brewer, Gerard Duménil, Duncan Foley, Heinz Kurz, David Laibman, Costas Lapavitsas, Jordi Massó, Lefteris Tsoulfidis, the participants of the UAB macroeconomics workshop, the Congres Marx International III, and the ESHET 2002 Conference, several anonymous readers, the referees of this journal and the Editor, Gary Mongiovi. I am grateful for their help. The usual disclaimer applies. Financial aid from DGI project SEC 2000-0684 is gratefully acknowledged.

${ }^{2}$ The references in this paragraph are as follows: TSV is Marx (1972). The Hodgskin section is Marx (1972, pp. 263-319). Volume III of Capital is Marx (1959). Part III of this last work is Marx (1959, 211266). The 350 notebook pages are Marx and Engels (1989, pp. 449-543) and (1991, pp. 7-252). The
} 
general law section is Marx and Engels (1991, pp. 104-152). Finally see footnote 121 of Marx and Engels (1989) for the editors' opinion of the relation between the 350 notebook pages and Volume III of Capital. ${ }^{3}$ A justification for not calling this the organic composition of capital is given in the section where the mathematical framework is set out.

${ }^{4}$ Marx habitually uses the phrase "the tendency for the rate of profit to fall". This has two interpretations: first that the rate of profit must fall in the long run but might rise during short periods; and second, that it is probable that it will fall in the long run but that it might not. When it is clear that Marx has in mind the first interpretation I will write "must fall". In the other case it will be "might fall".

${ }^{5} k$ seems like a good symbol for capital productivity in spite of its usual use.

${ }^{6}$ One could call this the organic composition of capital. But the issue is complicated. First Marx uses the phrase "the ratio of variable to constant capital" in both the Hodgskin and general law sections which are the focus of this paper. Second, since the model only has one good, the technical, value and organic compositions of capital are all equivalent. Third, there is a large literature on the roles of the different compositions (see Sadd-Filho, 2002, Ch. 6) and the reader might easily think that it was significant that I had chosen the organic composition. It seems best to follow Duménil \& Lévy (forthcoming) and avoid these issues by simply calling $C / V$ the composition of capital.

${ }^{7}$ In the Hodgskin section Marx slides over the link between the rising $K / L$ ratio and the rising $C / V$ ratio. In the general law section he just starts with the rising $C / V$ ratio. But in the Cherbuliez section of TSV, Marx (1972, pp. 362-398), he studies the link. In the two sections covered here the tenure of the writing is that it is the change in $K / L$ that causes the change in $C / V$.

${ }^{8} \tilde{l}^{\prime}=d \tilde{l} / d(C / V)$ and similarly for $\tilde{k}^{\prime}$ below.

${ }^{9}$ The actual text has "and" rather than "by".

${ }^{10}$ The actual text has "it" instead of "the productivity of capital"

${ }^{11}$ I have deleted the rise in the productivity of capital from the condition. This must be a slip by Marx since if the productivities of both capital and labour rose the rate of profit must also rise. This is obvious but can also be seen from (10).

${ }^{12}$ The editor refers to p. 439 and p. 596 of Part II of TSV, Marx (1968).

${ }^{13}$ The actual quote reads "if, as in the above example, the value of 12 hours is 75 then that of 24 hours adds up to $2 \times 75$ or 150 . And since a worker must live he can never produce 150 profit much less 200." I have corrected two slips to ease the reader's task. The first is of translation "as...is" is clearly wrong because in the above example the value of 12 hours is 25 . The second is in Marx's calculation. Clearly he was thinking that the rate of profit in the above example was 100 percent while it was actually 50 percent.

${ }^{14}$ Marx's notation here is that $c$ and $v$ are constant and variable capital, $C=c+v$, $p$ 'is the rate of profit and $s$ ' is the rate of surplus value.

${ }^{15}$ The edges of these pages have been damaged so that the transcription has such frequent gaps that Marx's argument is impossible to follow. I have reconstructed the pages. The complete reconstruction is in Appendix II of Petith (2001). The quotes that follow are taken from this reconstruction, the phrases in square brackets are the ones that I have added.

${ }^{16}$ This example suffers from the same problem as that of section 3.2. But Proposition 3 has shown that the problem the example illustrates is a real one.

${ }^{17}$ The manuscript has 50 .

${ }^{18}$ Marx's calculation is slightly array since the undepreciated amount is 333 . The correct calculation would be $(37+150+80+0.05 \times 333)(1.05)=326$. By this method the price in the first case would be $600 \times 1.05=630$. These details do not alter the thrust of Marx's calculations.

${ }^{19}$ There are sketches of multi-sector arguments which usually are based on resource scarcity, but these are outside the scope of the paper.

${ }^{20}$ Notebook 15 covers 208 pages. 